\title{
Logical Architecture Framework of Air-Rail Intermodality System
}

\author{
W. LIU \& J. Ouyang \\ Comprehensive Transportation Institute, Civil Aviation University of China, Tianjin, China
}

\begin{abstract}
In China, research and development of air-rail intermodality transportation has not been fleshed out. This paper aims to provide a theoretical support for the development of air-rail intermodality. Firstly, the concept of air-rail intermodality system is put forward. Without regard to management system and technical factors, but from a logical point of system function, we describe the internal structure of the system using hierarchical data flow diagram (DFD) and process oriented method for the first time. Based on the function of air-rail intermodality system, the top-level logical architecture framework is built, which is composed of seven subsystems. They are defined and explained respectively. At last, the two main service modulesintegrated ticketing system and through baggage handling system are described in detail.

KEYWORDS: air-rail intermodality; logical architecture framework; integrated ticketing; through baggage handling
\end{abstract}

\section{INTRODUCTION}

Air-rail intermodality is essentially taking railway system as "regional aviation" service of the airport. Passengers could achieve effective interchange between rail and air through integration. Back in 1959, Brussels has already provided city check-in service. Therefore, the air-rail mode in Europe is much more extensive and sophisticated.

AIRail in Frankfurt Airport is one of the world's most sophisticated air-rail intermodality services. It started integration from Stuttgart and Cologne to Frankfurt Airport in 2001 and 2003 respectively (Qin \& Xu 2005). Lufthansa realized code-sharing by cooperating with Deutsche Bahn. So passengers could book tickets through Lufthansa's booking network. The schedule of the train station linked up with the flights. Besides, passengers could check in and register the baggage at the station.

But in China, due to a late start of air-rail intermodality, the research has now only stayed on the surface and lacked of a unified internal architecture framework, which will greatly restrict the development and popularization of air-rail intermodality system technology.

Huang (2008) identified the basic model of air-rail integration with centralized ticketing model, and analyzed the composition of intermodal system from the perspective of the management system and transport organization mode. Yu (2008) analyzed the security of checked baggage and connection of air and rail transportation, as well as designed the baggage processing model of air-rail intermodality in Yangtze River Delta.

In order to develop passenger integration in China, a complete air-rail intermodality system with a sound internal architecture framework needs to be built, which should be led by the government. So that it can achieve a close link and organic coordination between railway and civil aviation systems.

\section{TOP-LEVEL LOGICAL ARCHITECTURE FRAMEWORK OF AIR-RAIL INTERMODALITY SYSTEM}

\subsection{Definition}

Air-Rail Intermodality System (as ARIS) is a comprehensive transportation system which integrates technology of electronics and information, computer, control and system, modern communication, management and system and so on, based on the achievement of information collecting, transmitting, processing and sharing during the operation, in order to ensure that the integration services could be carried out effectively and to improve transport efficiency.

If the system were just developed by rail or aviation authority, it would come cross permission 
problems, then data sharing and interworking would be completed. Therefore, the government should set up a special sector with the highest authority to lead development, maintenance, coordination and management of the system. Meanwhile, airports, airlines and railways need to set docking departments for communicating with air-rail intermodality management sector. They should also be provided appropriate authority, update, maintain and manage data in real time. Besides, coordination with travel agencies, hotels and other distribution units, websites, information service providers, baggage handling providers and other related units should be strengthened.

\subsection{Top-level Logical Architecture Framework}

Using the process oriented method (Jia et al. 2003), the top-level framework of ARIS needs to be put forward. Top-level logical architecture framework of ARIS (Fig. 1) defines seven subsystems that constitute air-rail intermodality system. They are: (1) Public Information System; (2) User Navigation System; (3) Electronic Commerce System; (4) Operation Management System; (5) Integrated Ticketing System; (6) Resources and Information Management System; (7) Through Baggage Handling System.

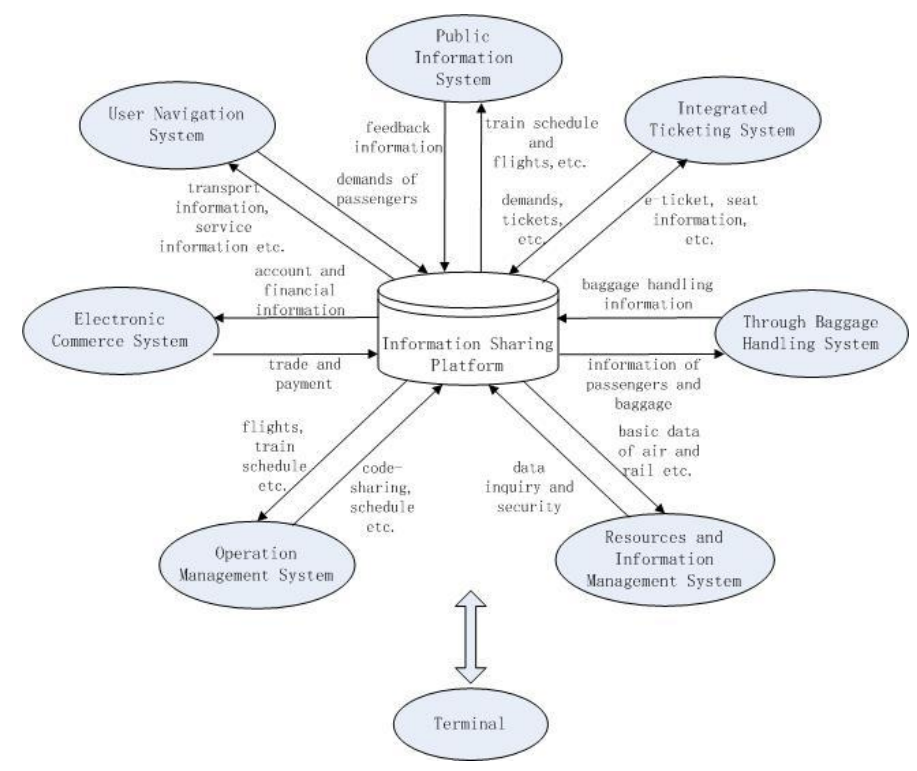

Figure 1. Logical Architecture Framework of ARIS

\subsection{Definition of the Subsystems}

The top-level framework contains all the functions in the whole air-rail transport process, as information release, information inquiry, information management, decision support, financial allocation, data collection, data sharing, integrated ticketing, code sharing, baggage handling and seat control etc.

Public Information System provides inquiry service for passengers and releases all kinds of travel information such as the train schedule, flights, fares as well as delays using the display screen, websites, messages, e-mails, etc. Also, it collects feedback from passengers by questionnaires and online evaluation, so to solve problems and improve services as soon as possible.

User Navigation System includes information guide facilities, unitizes and normalizes directions and indicators and provides information inquiry and navigation services within the air-rail building, steering passengers buying tickets, checking baggage, going through security, transferring, boarding and other activities quickly and reducing walking distance and crosstalk.

Electronic Commerce System realizes online booking, seat selecting, payment using information network system. It could also manage financial information through the interface with booking system, and auto-account online by automatic collecting system for sorting principles, receiving and setting parameters. In addition, through the management of the users' personal accounts, it can accumulate and redeem point. Air-rail intermodality sector will maintain and manage the financial data to ensure account security.

Operation Management System develops an optimized connection scheme of flights and trains by synthesizing needs of passengers and air-rail transport resources. Airport and air-rail building infrastructures are controlled uniformly. The system will achieve quality service and optimize the use of resources from a perspective of comprehensive operation management.

Integrated Ticketing System implements a multi-modal e-ticket. What passengers need is just a integrated ticket to go from the air-rail building to the airport and complete the whole process of security, customs, baggage checking and so on.

Resources and Information Management System collects, stores and manages passenger basic data, and provides decision support to help make plans. With complete contracts, protocols, laws and regulations, and unified standards, it establishes respective interface with railway and civil aviation databases, sharing and interchanging railway and civil aviation basic data in real time. Most importantly, a comprehensive information security mechanism needs to be established to ensure the safety of all databases.

By Through Baggage Handling System, passenger could check-in and check baggage in the air-rail building and take the train and plane to destinations. In the meanwhile, the baggage will be transported to the airport by purpose-built cars with large luggage accommodation for secondary screening and reach destinations by plane. If there is a problem during the secondary screening, passengers will be notified by messages, e-mails, automatic positioning, etc. 
Information Sharing Platform adopts a centralized information sharing way (Ren et al. 2009). Information services department signs cooperation agreements with transportation companies of air-rail intermodality, establishes a unified database, integrates and processes the information data. The users access the internal management server through system firewall. Data of all subsystems will be stored in the platform, so it needs a very sound information security mechanism.

\section{LOGICAL ARCHITECTURE FRAMEWORK OF MAIN SERVICE MODULES}

Of the seven subsystems, there are two main service modules- Integrated Ticketing System and Through Baggage Handling System- which are also the most important technical problems when developing air-rail intermodality system in the future.

\subsection{Logical Architecture Framework of Integrated Ticketing System}

Air-rail intermodality implements integrated ticket that is a multi-modal e-ticket. The railway authority set IATA codes for train stations and airlines can choose stations to sign code-sharing arrangements.
They can fix regional flight numbers or let passengers freely choose flight numbers according to their travel schedule.

There is a ticket center to integrate data and tickets, then sells tickets to passengers. Ticket proceeds are controlled by financial management department. Participants will get their benefits automatically according to their contribution and other parameters.

Integrated Ticketing System (Fig. 2) could make optimizing decisions for passengers according to their travel demands and related flights and train schedules. Intelligent optimization model will be established by computer to choose appropriate flight and train. It also processes seat reservation applications as well as generates, sends, receives, analyzes and commits relevant business information. After e-ticket is generated, it will connect with the E-commerce Trading Platform to pay online.

In an e-ticket the following items are contained: serial number; passenger name; ID number; origin station and code; destination station and code; ticketing date; ticketing station and code; effective date; intermodal information (flight and train number, origin and destination, class, seat information and fees); transfer information; baggage information and ticket prices.

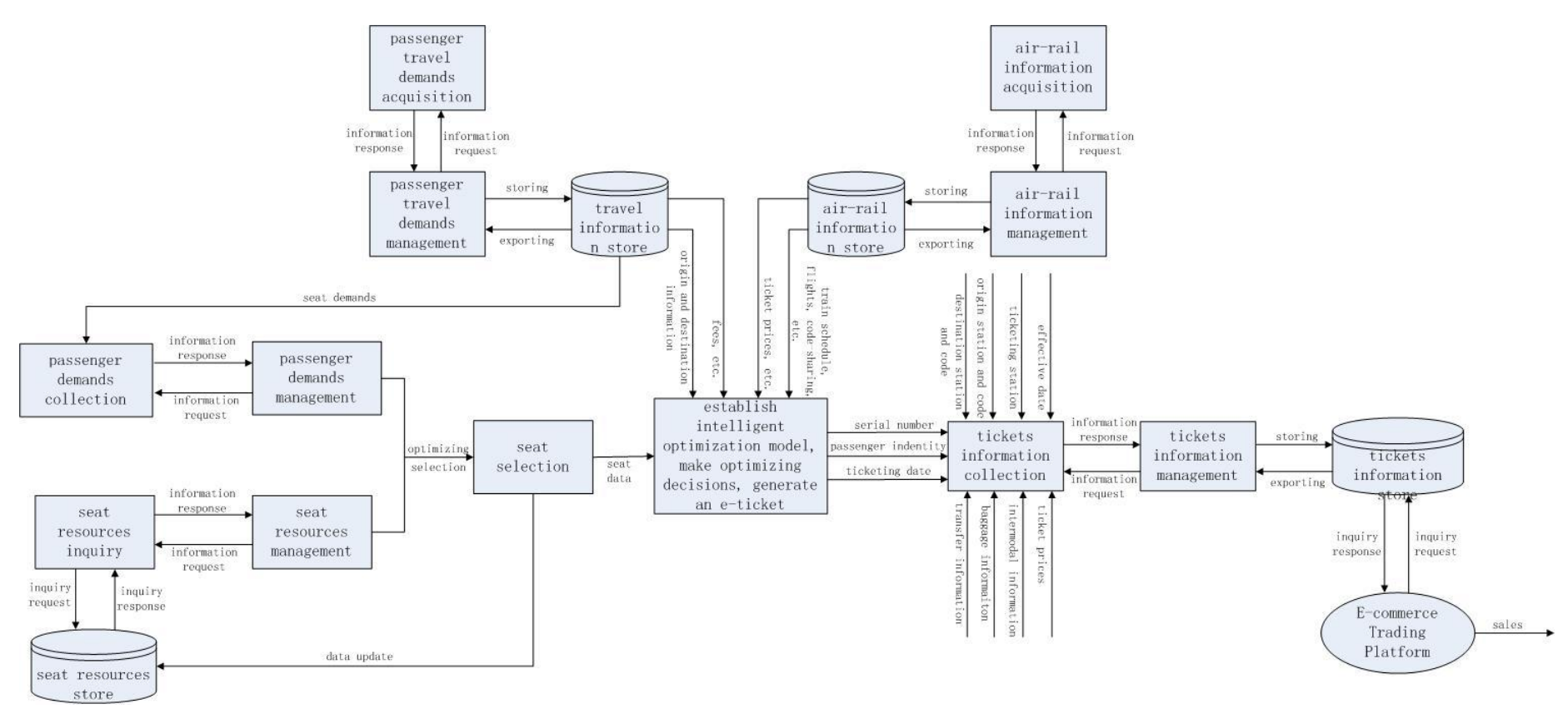

Figure. 2 Integrated Ticketing System

\subsection{Logical Architecture Framework of Through Baggage Handling System}

Through baggage handle is another big advantage of air-rail intermodality. Passengers check in with self-service machines and check baggage in the air-rail building. Baggage tags are equipped with automatic positioning chips and have passenger's phone number and e-mail address. After going through the security screening system for the first time in the air-rail building, the baggage will be sent to its terminal for secondary screening in a safe box in purpose-built cars with large luggage accommodation. There is an entire safe passage between the counter and the train. If there is any 
problem during secondary screening, the system will make phone calls, send text messages or send e-mails to the passenger. Or it will automatically position the passenger to broadcast in his region, even send staff to find him and so on. Because of the higher standard of air baggage than rail baggage, the secondary security mode can ensure the security of transport more effectively. While passengers are easier to reach their destinations by train and plane with less baggage trouble. See Figure 3.

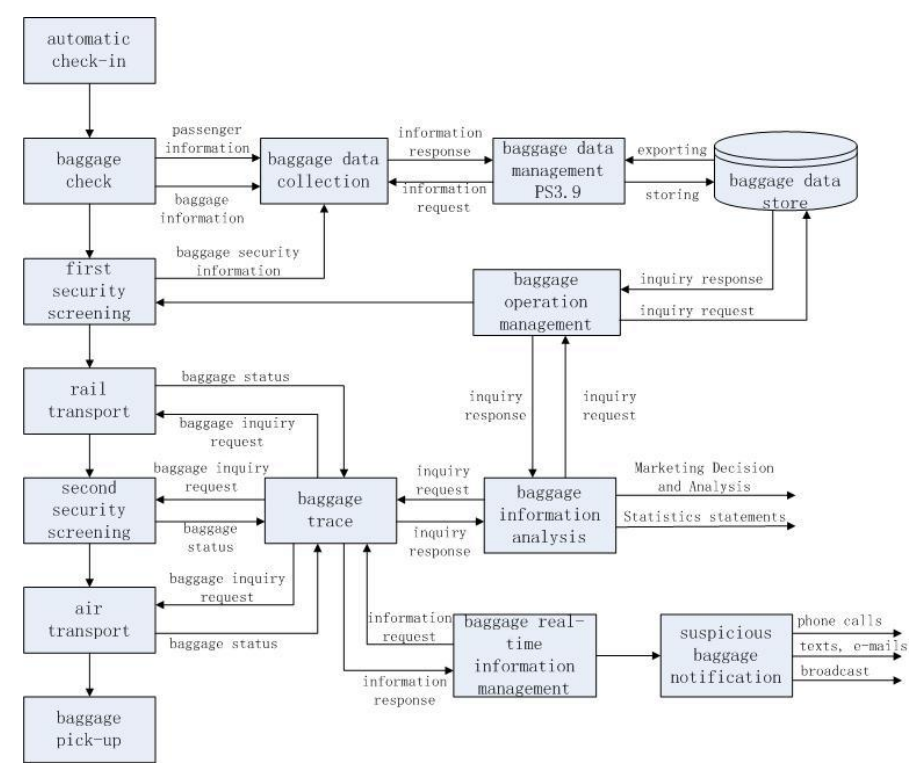

Figure 2. Through Baggage Handling System

\section{CONCLUSION}

Air-rail intermodality system is the foundation of integration development. In this paper, the top-level logical architecture framework is constructed, which has seven sub-systems and covers various functions in air-rail intermodality operation. Integrated Ticketing System and Through Baggage Handling System are the main service modules:

Integrated Ticketing System helps passengers to make optimizing decisions based on time and cost and manages seat resources;

Through Baggage Handling System provides baggage check service in the air-rail building so passengers could reach their destinations without heavy baggage trouble.

The proposed logical architecture framework of air-rail intermodality in this paper provides theoretical support for the construction of physical framework and development of air-rail integration technology in the future. A viable and sound air-rail intermodality intelligent transport system is also needed under the consideration of technical factors and management system.

\section{REFERENCES}

[1] QIN C C, XU D C. 2005. Air-rail Intermodality in Frankfurt Airport. Traffic \& Transportation, 02:46-49.

[2] HUANG X. 2008. Feasibility Study on Passenger Transportation of Air-rail Integration. Tongji University.

[3] REN P, XU R H, TAO Y J. 2009. Construction of Air-rail Intermodality Information Sharing Platform. Journal of Transport Information and Safety, 01:109-112.

[4] YU M. 2008. Study on Processing of Baggage in Air-rail Intermodality in Yangtze Delta. Tongji University.

[5] JIA L M, LI P, QIN Y, SHI T Y, NIE A X. 2003. Architecture Framework of Railway Intelligent Transport System of China. Chinese Railways, 09:22-26. 